incidence of 1 in $7 \cdot 5$ compared with 1 in 160 men by age 25 as reported by Williamson. ${ }^{2}$ Further evidence that these patients form a high risk group for torsion is provided by other authors who have noted a history of recurrent testicular pain before torsion in $29-50 \%$ of their patients. ${ }^{34}$ Recognition of this diagnosis, its relation to acute torsion and urgent elective orchidopexy may improve testicular salvage rates.

The occurrence of one case of torsion despite previous fixation with absorbable sutures suggests that fixation should be achieved with three non-absorbable sutures in addition to plication of the tunica vaginalis.

1 Van der Poel J. Strangulation of the testis and epididymis from torsion of the

spermatic cord. Med $\operatorname{Rec} 1895 ; 47: 742$.
2 Williamson RCN. Torsion of the testis and allied conditions. Br 7 Surg 1976;63:465-76.

3 Chapman RH, Walton AJ. Torsion of the testis and its appendages. Br Med $\mathcal{f}$ 1972;i:164-6.

4 Whitaker RH. Torsion of the testis. Br f Hosp Med 1982;27:66-9.

(Accepted 15 April 1988)

\title{
Convulsions associated with prophylactic antimalarial drugs: implications for people with epilepsy
}

\section{R Fish, M L E Espir}

\begin{abstract}
Institute of Neurology, Queen Square, London WC1N 3BG

D R Fish, MRCP, clinical lecturer

M L E Espir, FRCP, consultant neurologist
\end{abstract}

Correspondence to: Dr Fish.
With the increase in foreign travel it is not uncommon for patients with epilepsy to seek advice about malaria prophylaxis, but no special guidelines are available. We describe four patients who presented with tonicclonic seizures when taking antimalarial drugs prophylactically.

\section{Case reports}

Case 1-A 40 year old previously healthy woman had two tonic-clonic convulsions within three hours, 33 days after beginning prophylactic treatment with chloroquine sulphate $400 \mathrm{mg}$ and dapsone $100 \mathrm{mg}$ with pyrimethamine $12.5 \mathrm{mg}$ (Maloprim) once a week. Her subsequent electroencephalogram showed brief generalised spike and wave activity of $3 \mathrm{~Hz}$. She began carbamazepine and remained seizure free for four months.

Case 2-A 26 year old woman had her first tonicclonic seizure 23 days after beginning chloroquine two tablets and dapsone $100 \mathrm{mg}$ with pyrimethamine 12.5 $\mathrm{mg}$ (Maloprim) once a week. She had taken these drugs during previous foreign visits without adverse effects. For the past nine years she had suffered infrequent attacks in which she would be inaccessible for a few seconds, sometimes associated with myoclonic jerks. Physical examination showed nothing abnormal. Her subsequent electroencephalogram showed episodes of generalised spike and wave discharges of $3 \mathrm{~Hz}$. She began sodium valproate and remained seizure free for five months.

Case 3-A 49 year old woman presented with a prolonged tonic-clonic convulsion one day after taking chloroquine sulphate $400 \mathrm{mg}$. She had a long history of complex partial seizures, which were well controlled with carbamazepine. Previous electroencephalograms had shown focal sharp waves in the right temporal region. Her only previous generalised convulsion had occurred when she was 32 .

Case 4-A 26 year old previously healthy woman presented after two tonic-clonic seizures within one week. She had begun prophylactic treatment with sulfadoxine $500 \mathrm{mg}$ and pyrimethamine $25 \mathrm{mg}$ (Fansidar) once a week the previous month, but chloroquine two tablets a week had been added because of her itinerary. Her subsequent electroencephalogram was normal and over the next 14 months she remained seizure free without antiepileptic treatment.

The table summarises these four cases.

\section{Comment}

The association between malaria prophylaxis and tonic-clonic seizures is unlikely to have been due to chance. Three of the patients (cases 1,2, and 4) had never had tonic-clonic seizures before, even though two of them (cases 1 and 2) had evidence of a low seizure threshold. In case 3 the patient had had only one other tonic-clonic seizure many years previously. No patient had a further tonic-clonic seizure after stopping antimalarial drugs, but the seizures had serious consequences in each case and none of the patients was rechallenged.

All the patients were women. Convulsions have been reported in four women with amoebiasis receiving much higher therapeutic doses of chloroquine phosphate (500-1125 mg/day) in combination with diiodohydroxyquinoline or paromomycin and all showed signs of toxicity before the convulsions.' Very high doses of chloroquine ${ }^{2}$ and pyrimethamine ${ }^{3}$ have been reported to cause convulsions. We, however, have been unable to find any report of convulsions attributed to prophylactic doses of these drugs, and our search included contact with appropriate pharmaceutical companies and the Committee on the Safety of Medicines.

The mechanism of seizures induced by antimalarial drugs is uncertain. Chloroquine inhibits glutamate dehydrogenase activity,' so could reduce concentrations of the inhibitory neurotransmitter $\gamma$-aminobutyric acid.

We recommend that specific inquiry should be made for a history of epilepsy when considering malaria prophylaxis and that people with epilepsy should be

Characteristics of four patients who had tonic-clonic seizures while taking prophylactic antimalarial drugs

\begin{tabular}{|c|c|c|c|c|c|c|c|c|c|}
\hline \multirow{2}{*}{$\begin{array}{l}\text { Case } \\
\text { No }\end{array}$} & \multirow[b]{2}{*}{ Sex } & \multirow{2}{*}{$\begin{array}{c}\text { Age } \\
\text { (years) }\end{array}$} & \multirow[b]{2}{*}{ Drug } & \multirow[b]{2}{*}{ Dose/week } & \multirow{2}{*}{$\begin{array}{c}\text { No of doses } \\
\text { before tonic-clonic } \\
\text { seizure }\end{array}$} & \multicolumn{2}{|c|}{ Previous history of seizures } & \multirow[b]{2}{*}{ Electroencephalogram } & \multirow{2}{*}{$\begin{array}{l}\text { Subsequent } \\
\text { follow up } \\
\text { (months) }\end{array}$} \\
\hline & & & & & & Tonic-clonic & Other & & \\
\hline 1 & $\mathrm{~F}$ & 40 & $\left\{\begin{array}{l}\text { Chloroquine } \\
\text { Dapsone-pyrimethamine }\end{array}\right.$ & $\begin{array}{l}2 \text { Tablets` } \\
1 \text { Tablet }\end{array}$ & $\left.\begin{array}{l}5 \\
5\end{array}\right\}$ & 0 & 0 & $3 \mathrm{~Hz}$ spike/wave & 4 \\
\hline 2 & $\mathrm{~F}$ & 26 & $\left\{\begin{array}{l}\text { Chloroquine } \\
\text { Dapsone-pyrimethamine }\end{array}\right.$ & $\begin{array}{l}2 \text { Tablets* } \\
1 \text { Tablet }\end{array}$ & $\left.\begin{array}{l}4 \\
4\end{array}\right\}$ & 0 & Absence seizures & $3 \mathrm{~Hz}$ spike/wave & 5 \\
\hline 3 & $\mathrm{~F}$ & 49 & Chloroquine & 2 Tablets ${ }^{\star}$ & 1 & 1 & Complex partial seizures & Right temporal sharp waves & 1 \\
\hline 4 & $\mathrm{~F}$ & 26 & $\left\{\begin{array}{l}\text { Chloroquine } \\
\text { Sulfadoxine-pyrimethamine }\end{array}\right.$ & $\begin{array}{l}2 \text { Tablets* } \\
1 \text { Tablet }\end{array}$ & $\left.\begin{array}{l}2 \\
5\end{array}\right\}$ & 0 & 0 & Normal & 14 \\
\hline
\end{tabular}

${ }^{\star}$ Chloroquine: One tablet $=150 \mathrm{mg}$ base 
advised about the risk of antimalarial drugs provoking seizures. In view of the risk and the serious consequences if tonic-clonic seizures are provoked, some people with epilepsy may prefer to plan their itinerary so that they avoid the need to take antimalarial drugs.
1 Torrey EF. Chloroquine seizures. JAMA 1968;204:867-70. 2 Kiel FW. Chloroquine suicide. JAMA 1964;190:398-400.

3 Grisham RSC. Central nervous system toxicity of pyrimethamine (Daraprim) in man. Am f Ophthalmol 1962;54:1119-21.

(Accepted 5 May 1988)

\section{Mediastinal haemorrhage: a complication of thrombolytic treatment}

\section{K P Suddes, R D Thomas}

Royal United Hospital, Bath, Avon BA1 3NG K P Suddes, MB, medical registrar

R D Thomas, MD, consultant physician

Correspondence to:

DrThomas. plasminogen activator.

\section{Case report}

Thrombolytic treatment is a major advance in acute myocardial infarction.' The most serious side effect is haemorrhage, and we report a case of mediastinal and pericardial bleeding after the administration of tissue

A 48 year old man presented with severe retrosternal chest pain of two hours' duration. Examination did not show any abnormality. An electrocardiogram showed poor $R$ wave progression and ST segments raised $1.5 \mathrm{~mm}$ in the chest leads. A chest radiograph was normal. Myocardial infarction was thought the most likely diagnosis and he was entered into a trial of thrombolytic treatment. He was given a bolus of 5000 IU heparin and then the trial drug (later shown to be tissue plasminogen activator) over two hours, followed by heparin infusion for 24 hours. Nine hours after admission he developed typical pericardial pain

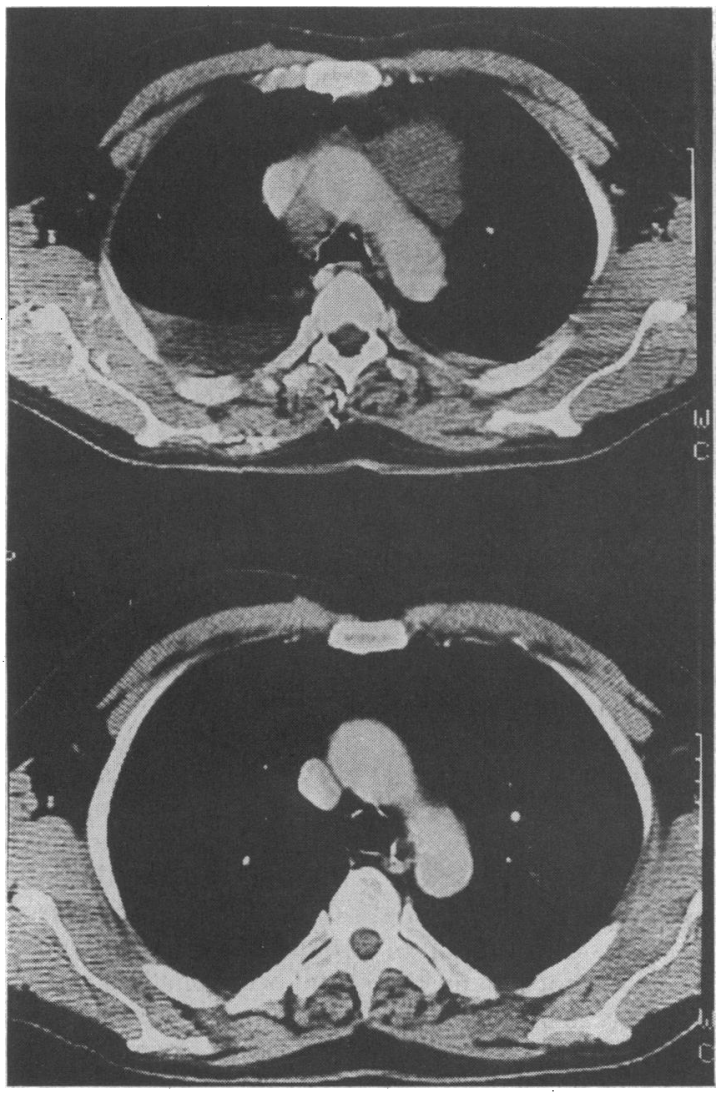

Computed tomograms showing soft tissue mass in anterior mediastinum beside aorta (top) and its resolution three months later (bottom) and was given $50 \mathrm{mg}$ indomethacin orally. Two hours later he became ill with severe chest pain, a heart rate of 140 beats/minute, and a profound fall in systemic blood pressure. The jugular venous pressure was raised $4 \mathrm{~cm}$ above the sternal angle and there was $15 \mathrm{~mm} \mathrm{Hg}$ of paradox. The heart sounds were normal, the electrocardiogram was unchanged, and two dimensional echocardiography showed a small pericardial effusion. The kaolin cephalin clotting time was normal.

We thought that he had pericardial tamponade, but pericardial aspiration produced only $5 \mathrm{ml}$ of heavily bloodstained fluid. His condition improved over the next few hours; further electrocardiograms showed non-specific ST-T change, and serial measurements of cardiac enzyme activity were normal. The next morning a chest radiograph showed appreciable widening of the superior mediastinum. Computed tomography showed a low density mass in the anterior mediastinum, a small pericardial effusion, and a small pleural effusion (figure). As there was a risk of dissecting aortic aneurysm he was transferred to the regional centre for urgent aortography and coronary angiography, which both yielded normal results. Haematological variables, plasma viscosity, viral titres, and autoantibody titres were normal.

At follow up at three months the patient was well and a chest radiograph and computed tomogram were normal.

\section{Comment}

The most serious complication of thrombolytic treatment is bleeding: treatment has to be stopped or a transfusion given in $1-2 \%$ of patients. ${ }^{2}$ This man's primary illness was acute pericarditis, but the main adverse events were iatrogenic mediastinal haemorrhage and pericardial haemorrhage. Mediastinal haemorrhage is rare and is usually the result of trauma or ruptured aortic aneurysm; it rarely occurs in bleeding disorders. Probable mediastinal haemorrhage after intracoronary administration of streptokinase and heparin has been described, ${ }^{3}$ but the patient had been investigated by cardiac catheterisation, itself a cause of mediastinal haemorrhage, and the diagnosis was not proved. In addition, the hazards of thrombolytic treatment in patients with acute pericarditis have been described, with the delayed development of pericardial tamponade. ${ }^{4}$ If thrombolytic treatment becomes more widely used its potential danger in conditions mimicking myocardial infarction must be realised and the complication of mediastinal haemorrhage recognised.

1 Richards T. Seconds may count. Br Med J 1987;295: 198-9.

2 Yusuf $\mathrm{S}$, Collins R, Peto R, et al. Intravenous and intracoronary fibrinolytic therapy in acute myocardial infarction: overview of results on mortality, reinfarction and side-effects from 33 randomized controlled trials. Eur Heart f 1985;6:556-85.

3 Singh S, Ptacin MJ, Bamrah VS. Spontaneous mediastinal haemorrhage; complication of intracoronary streptokinase infusion for coronary thrombosis. Arch Intern Med 1983;143:562-3.

4 Tilley WS, Harston WE. Inadvertent administration of streptokinase to patients with pericarditis. $A m \mathcal{F}$ Med 1986;81:541-4.

(Accepted 3 May 1988) 